Gut, 1961, 2, 323

\title{
The intestinal absorption defect in cystinuria
}

\author{
M. D. MILNE, A. M. ASATOOR ${ }^{1}$, K. D. G. EDWARDS ${ }^{2}$, AND \\ LAVINIA W. LOUGHRIDGE \\ From the Departments of Medicine and Chemical Pathology, Postgraduate \\ Medical School of London
}

SYNOPSIS This paper brings forward evidence to suggest that the amino-acid transport defect known to occur in the kidneys of cystinurics is also present in the gut.

Cystinuria was first described 150 years ago (Wollaston, 1810) and numerous theories have since been advanced to explain the clinical and biochemical abnormalities of the disease. The present view of the disorder (Dent and Rose, 1951) is that cystinuria is a disease of the kidney tubules, involving reduced reabsorption by the renal tubule cells from the glomerular filtrate of the dibasic amino-acids-cystine, lysine, arginine, and ornithine. No other tubular defect has been found, implying a specific defect of amino-acid transport in kidney cells. We consider this to be a correct but incomplete view of the disordered physiology of the disease, and describe experimental evidence for a more generalized defect, possibly involving amino-acid transport in all body cells. This wider concept explains many previous observations not easily reconciled with the current more restricted view of the disease.

Cystinuria is a recessive hereditary disease (Dent and Harris, 1951; Harris and Warren, 1953; Harris, Mittwoch, Robson, and Warren, 1955a and b; Harris and Robson, 1955), such conditions usually involving a deficiency or absence of a single protein, which may be an enzyme. The biochemical defect in Hartnup disease (Baron, Dent, Harris, Hart, and Jepson, 1956; Milne, Crawford, Girão, and Loughridge, 1960), a comparable recessive hereditary condition, is a reduced ability to transport those amino-acids which are not involved in the transport defect of cystinuria. The defect in Hartnup disease has been shown to involve cells both of the proximal renal tubules and of the jejunum. This paper presents evidence that cystinuria and Hartnup disease are closely related conditions, each comprising a specific hereditary disorder of amino-acid transport. The dibasic amino-acids-cystine, lysine,

\footnotetext{
'Miles-Ames research fellow.
}

${ }^{2}$ Postgraduate Foundation fellow of the University of Sydney. arginine, and ornithine-are involved in cystinuria, and most of the other amino-acids derived from protein hydrolysis, with the notable exceptions of glycine and proline, in Hartnup disease.

\section{MINOR METABOLIC PATHWAYS OF LYSINE AND ORNITHINE}

Our experimental plan makes use of minor pathways of lysine and ornithine metabolism and is impossible to explain without a previous short review of existing knowledge. Lysine, if not utilized in protein synthesis, is normally oxidized to $\alpha$-keto- $\dot{\epsilon}$-aminocaproic acid. This is then metabolized by a chain of reactions to $\alpha$-ketoglutaric acid, and thus to the tricarboxylic acid cycle (Rothstein and Miller, 1954). Arginine and ornithine are involved in the cyclic series of reactions in the formation of urea (Krebs and Henseleit, 1932). The present work is not concerned with these major pathways of metabolism.

Many bacteria, including numerous organisms of the normal colonic flora, break down lysine, arginine, and ornithine, by the action of specific decarboxylases, to the corresponding diaminescadaverine, agmatine, and putrescine. These decarboxylases are most active at an acid reaction (Gale, 1940a), the optimum $p \mathrm{H}$ being 4.0 for arginine decarboxylase, 4.5 for lysine decarboxylase, and 5.0 for ornithine decarboxylase. In this investigation we have never detected agmatine either in faeces or urine, either because arginine itself was not administered or because of the low $p \mathrm{H}$ optimum of the appropriate decarboxylase. The formation and further metabolism of cadaverine and putrescine is shown to be of considerable importance in cystinuria, confirming earlier work (von Udránszky and Baumann, 1889; Garrod, 1908). A summary scheme of the further metabolism of the diamines is given in Fig. 1. 
METABOLISM OF LYSINE VIA CADAVERINE FORMED BY COLONIC BACTERIA
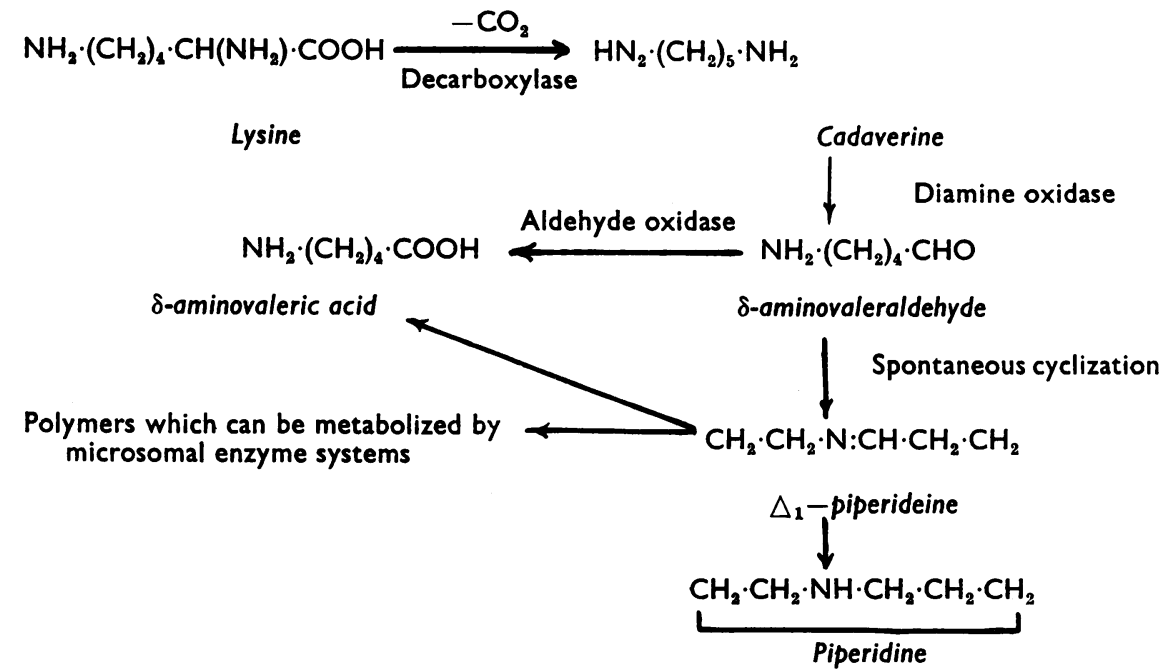

METABOLISM OF ARGININE AND ORNITHINE VIA PUTRESCINE FORMED BY COLONIC BACTERIA

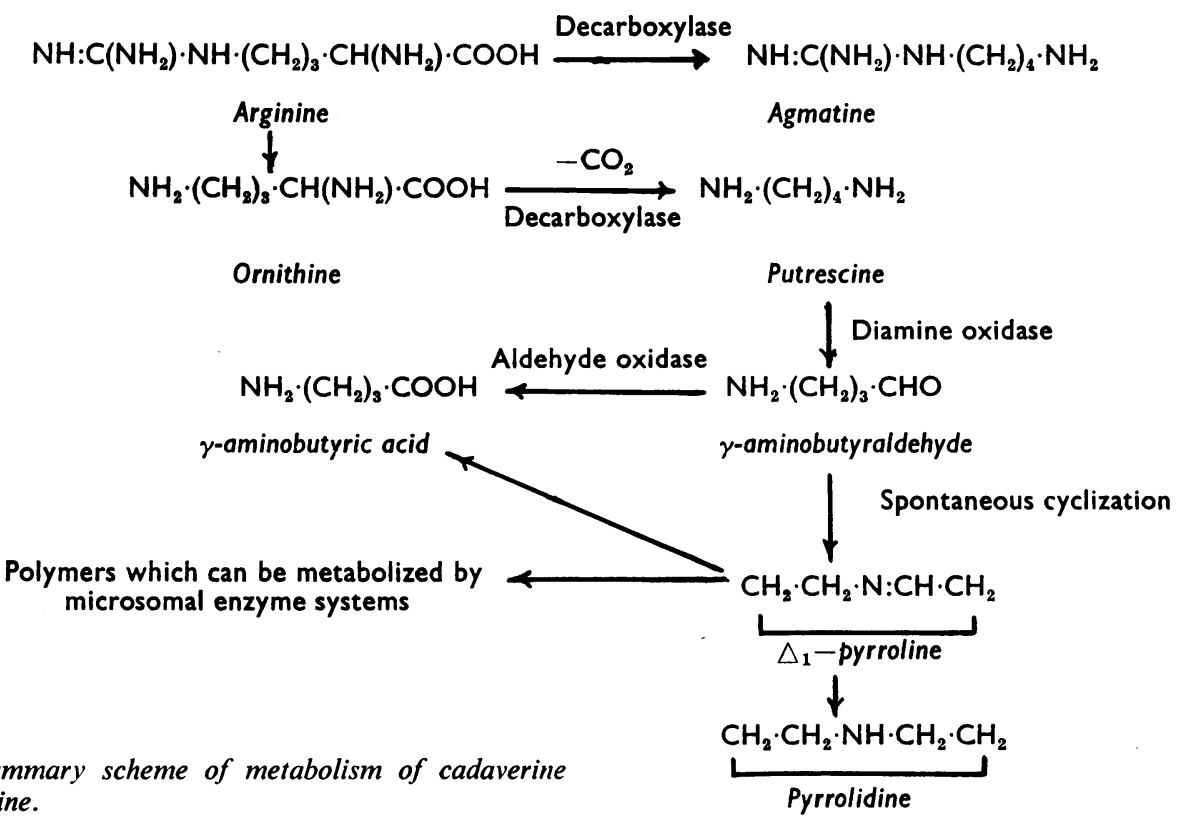

FIG. 1. Summary scheme of metabolism of cadaverine and putrescine.

The diamines are readily absorbed from the colon, and are oxidized by diamine oxidase to the corresponding aldehydes, $\delta$-aminovaleraldehyde and $\gamma$-aminobutyraldehyde. The greater proportion of these aldehydes is oxidized by aldehyde oxidase to the corresponding amino-acids, $\delta$-aminovaleric acid and $\gamma$-aminobutyric acid, both of which can be fully metabolized to $\mathrm{CO}_{2}$ and urea. The aldehydes, however, are highly reactive compounds, and spontaneously cyclize to the unsaturated heterocyclic amines, $\Delta_{1}$-piperideine and $\Delta_{1}$-pyrroline. Polymers of these amines are formed when the diamines are incubated with diamine oxidase of plant origin (Mann and Smithies, 1955). Suzuki and Hagihara 
(1954) performed similar experiments using diamine oxidase prepared from hog kidney, and claimed that the saturated heterocyclic amines, piperidine and pyrrolidine, were formed. Asatoor and Milne (1961) confirmed the production of these saturated amines, but also detected considerable quantities of the polymers of $\Delta_{1}$-piperideine and $\Delta_{1}$-pyrroline by use of the methods of Mann and Smithies (1955). When injected into rats these polymers were found to be rapidly metabolized by microsomal enzyme systems, only $1-2 \%$ of the injected dose being excreted in the urine. Strecker (1960) has recently shown that both $\Delta_{1}$-piperideine and $\Delta_{1}$-pyrroline can also be oxidized by a mitochondrial enzyme to $\delta$-aminovaleric and $\gamma$-aminobutyric acids respectively. The highly reactive unsaturated heterocyclic amines are therefore probably metabolized in three ways: 1 , Spontaneous polymerization, and metabolism of the polymers by microsomal enzymes; 2 , oxidation by a mitochondrial enzyme to $\omega$-aminoacids; and 3 , reduction to the saturated heterocyclic amines, piperidine and pyrrolidine.

The urinary excretion of these saturated heterocyclic amines by man was first noted by von Euler (1945), who recorded a total output of 3 to $20 \mathrm{mg}$. per day. This paper shows that formation of piperidine is dependent on bacterial metabolism within the colon of unabsorbed lysine to cadaverine, and that pyrrolidine formation depends on similar bacterial metabolism of arginine and ornithine. The reaction chains are completely specific, and therefore pyrrolidine cannot be formed from lysine nor can piperidine from arginine or ornithine. Colonic bacteria can readily convert arginine to ornithine (Gale, 1940b) and, probably because of the highly acidic $p \mathrm{H}$ optimum of arginine decarboxylase, this is a more important metabolic pathway that direct decarboxylation of arginine to agmatine. Excess excretion of the saturated heterocyclic amines by cystinurics is shown to be an important but hitherto undescribed aspect of the disease.

\section{METHODS}

Metabolic tests were carried out in five homozygous cystinuric patients, all giving a history of urinary calculus disease. One was a child of 8 and the others were adults. The results were compared with similar tests in 12 normal adult control subjects without evidence of renal or metabolic disease. Each test consisted of oral ingestion of a solution of either L-lysine or L-ornithine monohydrochloride, followed by serial analyses of urine and faecal specimens passed during the next 24 hours. Preliminary tests using $4 \mathrm{~g}$. L-lysine hydrochloride gave equivocal results and are not reported. L-lysine, $20 \mathrm{~g}$., was then given as two doses of $10 \mathrm{~g}$. at an interval of four hours. Half the dose was used in the cystinuric child. One cystinuric patient was given the same dose of L-ornithine hydrochloride, but this caused diarrhoea and abdominal colic. As reported later, the amount of potentially toxic metabolites produced was much greater than after an identical dose of L-lysine hydrochloride. In the other tests using L-ornithine hydrochloride, a single dose of $10 \mathrm{~g}$. was used.

The 24-hour metabolic tests to be reported comprise (a) tests on four cystinuric patients and 10 normal subjects receiving L-lysine; $(b)$ one cystinuric patient and one normal subject receiving L-lysine after pretreatment for three days with oral neomycin, $10 \mathrm{~g}$. daily; (c) two cystinuric patients receiving L-ornithine, $20 \mathrm{~g}$. and $10 \mathrm{~g}$. respectively, and two normal subjects receiving the smaller dose.

A two-hour basal specimen of urine was collected, in most cases from 7 a.m. to 9 a.m. The first dose of the amino-acid was then given, and separate two-hourly urine specimens were collected for the next 12 hours. Finally, an overnight 12-hour urine specimen was obtained. Separate faecal specimens were obtained, including the last specimen passed before the test, and all specimens passed spontaneously during the 24 hours of the metabolic tests. If faeces were not obtained during the 24-hour period, a glycerine suppository was given at the end of the test. All urine and faecal specimens were deep frozen immediately after collection.

CHEMICAL METHODS

AMINO-ACIDS IN FAECES The faeces were homogenized with four times their weight of acetone and then filtered. The acetone was evaporated off under reduced pressure, and the residue diluted with distilled water to a volume in millilitres equivalent to half the original faecal weight in grams. The resultant extract was filtered and $25 \mu \mathrm{l}$. chromatographed using butanol:acetic acid:water, $4: 1: 2$, as solvent. The amino-acid spots were developed either by ninhydrin or by a diacetyl-naphthol reagent for the guanidino-group.

DIAMINES IN FAECES The remainder of the faecal extract was mixed with one-fifth its volume of saturated ammonium reineckate solution. After standing for two hours the precipitated amine reineckates were removed by centrifugation and purified by recrystallization from acetone. A solution of the purified reineckates in acetone was then chromatographed using the same technique as described for faecal amino-acids.

DINITROPHENYL DERIVATIVES OF URINARY AMINES Dinitrophenyl (DNP) derivatives of urinary amines were prepared as described by Asatoor and Kerr (1961) and their subsequent chromatography as described by Asatoor (1960).

QUANTITATIVE ASSESSMENT OF TOTAL HETEROCYCLIC AMINE CONTENT OF URINE The amount of urine corresponding to a 10-minute period was diluted to $25 \mathrm{ml}$. with distilled water. This was saturated with excess $\mathrm{NaCl}$ and $5 \mathrm{ml} .20 \% \mathrm{NaOH}$ was added. The 
solution was extracted with $20 \mathrm{ml}$. chloroform. The chloroform layer was separated by centrifugation and dried over anhydrous sodium sulphate. The solution. was then shaken with an equal volume of $\mathrm{N} / 10 \mathrm{HCl}$. Two $\mathrm{ml}$. of the acid phase was then neutralized with $\mathrm{N} \mathrm{NaOH}$ and the solution made up to $3 \mathrm{ml}$. with distilled water. To this was added $2 \mathrm{ml} .2 \%$ sodium borate, $5 \mathrm{ml}$. ethanol, and $1 \mathrm{ml}$. freshly prepared $0.5 \%$ solution of the sodium salt of $1: 2$ naphthoquinone-4-sulphonic acid. After development at room temperature for 15 minutes, the colours were compared with standard piperidine or pyrrolidine solutions treated in an identical manner in a Unicam spectrophotometer at wavelengths 500 and $560 \mathrm{~m} \mu$. The absorption spectrum of the colour obtained from the heterocyclic amines has a steep gradient between these wavelengths, and maximum specificity was obtained by using the difference between the two readings. Piperidine standards were used in the experiments involving lysine, and pyrrolidine standards after ornithine. There was only a slight difference in the absorption obtained from each heterocyclic amine per mole. Cadaverine, but not putrescine or agmatine, was found to interfere somewhat in the method. An olive green colour is obtained from cadaverine in contrast to the rose colour produced by the heterocyclic amines. By comparing the absorption spectra of the solutions it was always possible to recognize urine specimens containing cadaverine as well as the more ubiquitous heterocyclic amines. The sensitivity of the method for cadaverine per mole was one-tenth that for the heterocyclic amines. Of the other amines in urine there was no interference from the primary aliphatic aminesmethylamine, ethylamine and iso-amylamine. Dimethylamine was, however, found to produce a colour similar to that of the heterocyclic amines, the sensitivity being almost identical for an equal weight of amine, but approximately twice as sensitive per mole in favour of the heterocyclic amines. Chromatography of the DNP derivatives showed that urinary dimethylamine content did not vary under the conditions of the experiments, whereas the heterocyclic amines were greatly increased by amino-acid ingestion. The method was therefore useful for assessing change in urinary piperidine plus pyrrolidine, but there was a constant blank value equivalent to an excretion of 0.7 to $1.3 \mathrm{mg}$. dimethylamine per hour in adults.

\section{RESULTS}

The results are summarized in Table I which, however, requires some explanation in the text. The first column gives the type of metabolic test, and the second the number of separate tests performed, as previously described in the 'methods' section. The incidence of diarrhoea is recorded in the third column. This was always unequivocal, the amino-acids either causing no change in the amount, frequency of voiding, or appearance of the faeces, or producing severe watery diarrhoea with voiding at half-hour intervals, and often accompanied by tenesmus and abdominal colic. The presence of part of the ingested amino-acid in faeces is recorded in column 4 . The chromatographic technique used fails to distinguish lysine from ornithine, and it was therefore assumed that the appearance in the faeces of an amino-acid of $R_{f}$ value identical to that given by mouth represented unabsorbed amino-acid (Fig. 2). Column 5 shows that the diamines were isolated by reineckate precipitation of faecal extracts more frequently in the cystinurics than in the normal controls. This correlates with the more frequent detection of the precursor amino-acids in the faeces of the cystinurics. Diamines were only found in the faeces of normal subjects on one occasion after lysine ingestion which caused intestinal hurry with watery diarrhoea. Fig. 3 shows a typical result from a normal subject and a cystinuric patient, cadaverine being detectable in the faeces of the patient only.

TABLE I

EFFECTS OF INGESTION OF L-IYSINE OR L-ORNITHINE MONOHYDROCHLORIDE IN FIVE HOMOZYGOUS CYSTINURIC PATIENTS AND 12 NORMAL CONTROLS

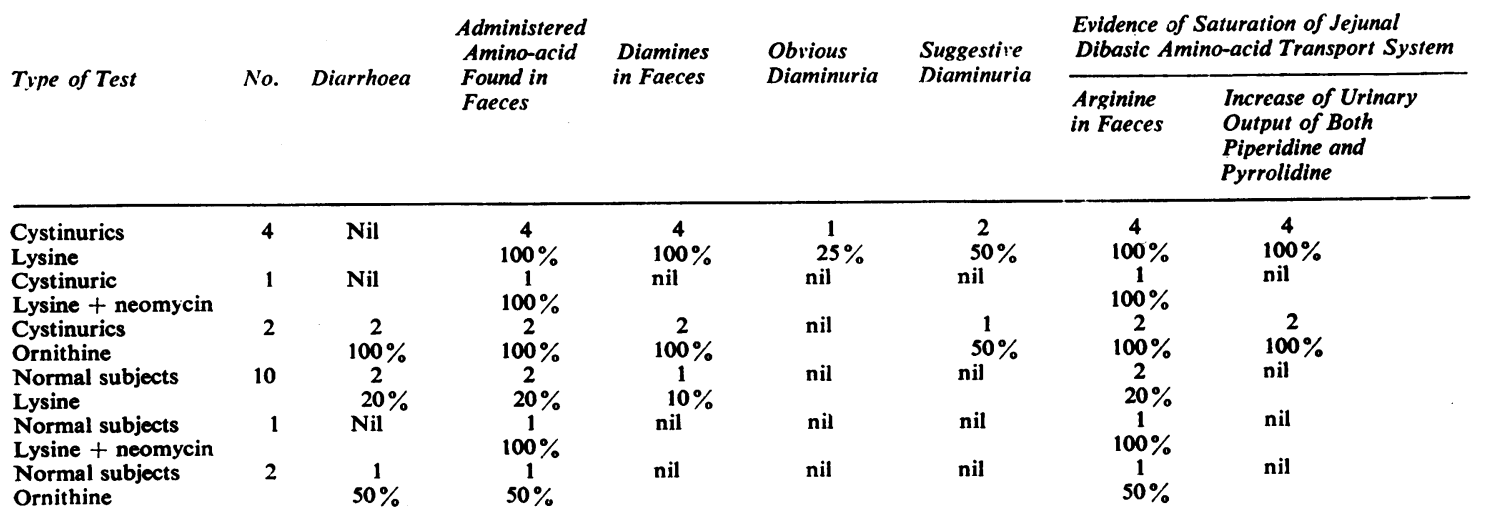


Columns 6 and 7 give the incidence of diaminuria. 'Obvious diaminuria' means that a urine specimen was obtained which gave a dense precipitate when mixed with a saturated solution of ammonium reineckate, and the purified precipitate was identified as cadaverine reineckate. The methods used in identification were chromatography (Fig. 3) and preparation of dibenzoyl-cadaverine by a combination of the methods of Zaimis (1950) and Simon (1900). This dibenzoyl derivative was shown to be identical with pure dibenzoyl-cadaverine by three methods: determination of the melting point $\left(135^{\circ} \mathrm{C}\right)$ both with and without admixture with the authentic compound, chromatography using butanol ethanol:2N ammonia, 7:1:2, as solvent, and by showing that the ultraviolet absorption spectrum was identical with that of the synthetic compound. 'Obvious diaminuria' is presumably comparable to that described by earlier workers and reviewed by Garrod (1908). The method is relatively insensitive as cadaverine must be in greater concentration than $0.2 \mathrm{mg} . / \mathrm{ml}$. before a reineckate precipitate is obtained. Diaminuria of this severity was found in only a single urine specimen obtained from a cystinuric eight to 10 hours after lysine ingestion. From the weight of reineckate obtained it could be calculated that $90 \mathrm{mg}$. cadaverine was excreted, corresponding to a conversion of $0.6 \%$ of ingested amino-acid to urinary diamine.

'Suggestive diaminuria' means that the colour and absorption spectrum of the solution obtained by the quantitative method for urinary amines was identical with that obtained from a mixture of cadaverine with either piperidine or pyrrolidine. The time relations of diaminuria are of importance. The specimen containing diamine was always a single two-hour collection obtained either two or four hours before the maximum output of heterocyclic amines, i.e., from six to 10 hours after the first dose of amino-acid. This proves that diaminuria after lysine or ornithine ingestion in cystinuric patients is a transient phenomenon, and precedes maximum output of the heterocyclic amines, as would be predicted from the metabolic pathways shown in Fig. 1.

This paper provides evidence of impaired transport of dibasic amino-acids by the small intestine of cystinuric patients. This implies that these aminoacids share a common transport system, and that this would be more easily saturated by excess of a single dibasic amino-acid than would the transport system of a normal subject. We report two connected experimental observations supporting this view. Column 8 in Table I gives the more direct evidence. Ingestion of either lysine or ornithine by both normal subjects and cystinurics may impair the intestinal absorption of arginine, which is readily distinguished from the ingested amino-acids by its higher $R_{f}$ value (Fig. 4 ) and by its reaction with the diacetyl-naphthol reagent for the guanidino-group. Arginine was recovered from the faeces in all tests in cystinuric patients, but in normal subjects only if there was intestinal hurry with watery diarrhoea or if intestinal transport had been temporarily impaired by pre-treatment with neomycin (Faloon, Fisher, and Duggan, 1958; Jacobson, Chodos, and Faloon, 1960). The last column of Table I contains more indirect evidence of saturation of intestinal transport, but is more conveniently described later together with the chromatograms of Figs. 8-10.

Figs. 2 and 3 give representative chromatographic results from which the data of Table $I$ have been compiled. The effects of neomycin shown in Fig. 4 are of especial interest. This antibiotic has been shown to have a reversible toxic action on the gut mucosa involving impaired absorption of fats, carbohydrates, vitamins, and nitrogenous compounds (Faloon et al., 1958; Jacobson et al., 1960). Chromatography of faecal extracts after neomycin showed a gross increase of unabsorbed amino-acids, including lysine and arginine. Ingestion of lysine after neomycin in normal subjects and cystinurics causes an increased faecal output of both lysine and arginine. The damaged transport system of the healthy subject taking neomycin is thus more easily saturated than without the drug. There are two differences from the intestinal defect in cystinuric patients; the defect is generalized rather than specific for a limited number of dibasic amino-acids, and the effect of the antibiotic on the colonic flora prevents the formation of diamines and their metabolic products.

Fig. 5 gives the mean urinary output of heterocyclic amines (piperidine + pyrrolidine) after lysine in the 10 normal subjects and the four cystinuric patients. The maximum output occurs in both groups from 10 to 12 hours after the first dose of the amino-acid, but there is also a high excretion in the overnight specimen, 12 to 24 hours afterwards. The total excess output of heterocyclic amines in the cystinurics averaged $35.6 \mathrm{mg}$. (S.D. $12.7 \mathrm{mg}$.), and in the normal subjects $18.4 \mathrm{mg}$. (S.D. $10.4 \mathrm{mg}$.). There is considerable variation in the individual results as expected from a biological process dependent on intestinal absorption, bacterial putrefaction, and subsequent absorption and metabolism of the diamines produced. The two excretion figures are not in fact significantly different at the conventional 1 in 20 level of probability, the $P$ value being $0 \cdot 1 \quad(t=1 \cdot 7)$. However, when the results of Figs. 5 and 7 are considered together, the difference is highly significant. The amount of 


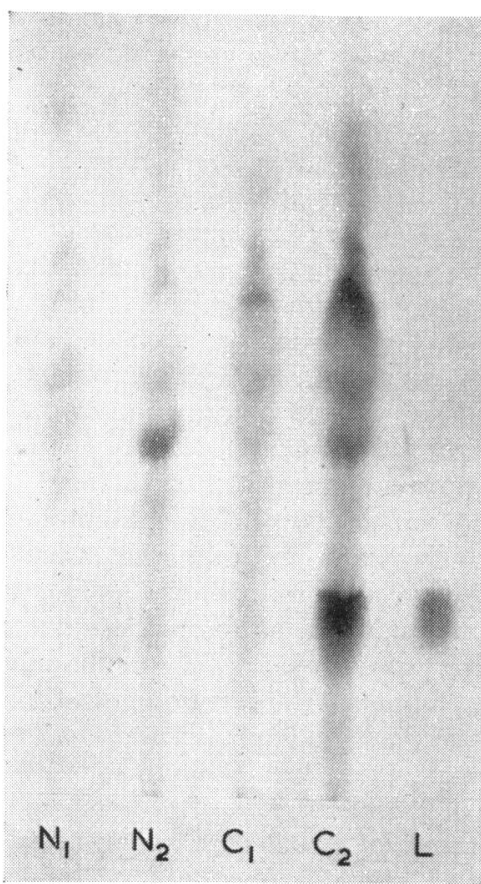

FIG. 2

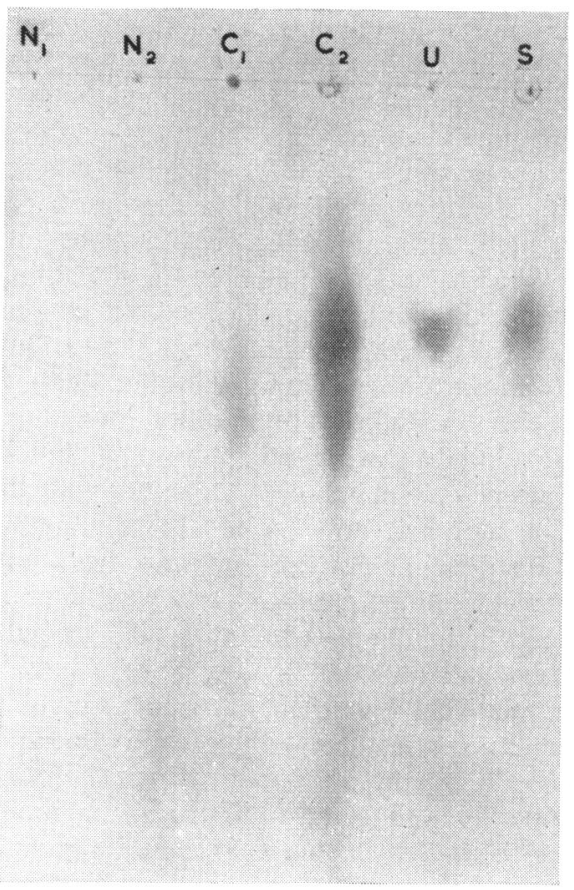

FIG. 3

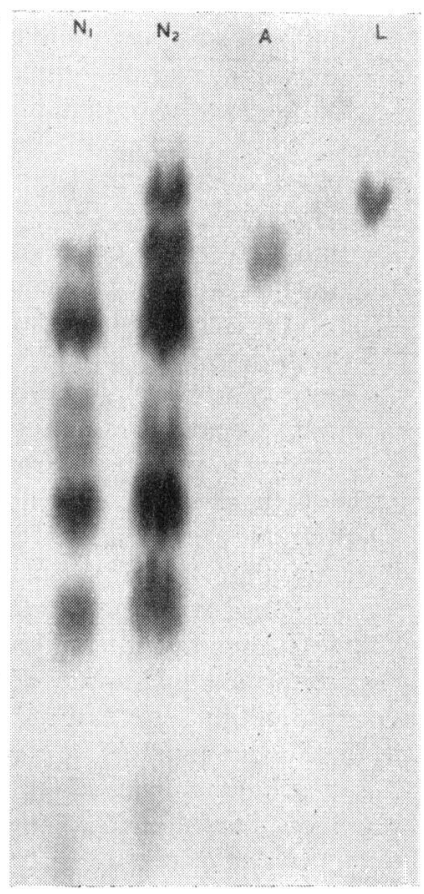

FIG. 4

FIG. 2. Chromatograms of faecal extracts. $N_{1}=$ normal subject before lysine; $N_{2}=$ after lysine; $C_{1}=$ cystinuric before lysine; $C_{2}=$ after lysine; $L=$ lysine marker. Butanol-acetic acid-water. Ninhydrin spray. There is only a slight increase of faecal lysine in the normal subject, but a great increase in the cystinuric.

FIG. 3. Chromatograms of amines in faecal extracts and urine after reineckate precipitation. $N_{1}=$ faecal extract of normal subject before lysine; $N_{2}=$ after lysine; $C_{1}=$ faecal extract of cystinuric before lysine; $C_{2}=$ after lysine; $U=$ urine of cystinuric after lysine; $S=$ cadaverine marker. Butanol-acetic acid-water. Ninhydrin spray. The faeces of the normal subject do not contain any detectable cadaverine either before or after lysine. There is some cadaverine in the faeces of the cystinuric before lysine and a great increase after ingestion of the amino-acid. Eight hours after lysine ingestion the cystinuric excreted considerable quantities of cadaverine in the urine.

FIG. 4. Chromatograms of faecal extracts. $N_{1}=$ normal subject taking neomycin before lysine ingestion; $N_{2}=$ after lysine; $A=$ arginine marker; $L=$ lysine marker. Butanol-acetic acid-water. Ninhydrin spray. The faeces of a normal subject taking neomycin contain considerable quantities of unabsorbed amino-acids. There is some lysine but a greater amount of arginine. After lysine ingestion there is increase of both lysine and arginine.

amine excreted is equivalent to a conversion of $0.4 \%$ of the ingested lysine in the cystinuric patients and of $0.2 \%$ in the normal subjects. The latter conversion is equivalent to that from the normal intake of lysine + arginine contained in dietary proteins. From 6 to $9 \mathrm{~g}$. of the amino-acids is ingested daily, and 3 to $20 \mathrm{mg}$. of piperidine plus pyrrolidine is excreted in the urine.

Fig. 6 gives the output of heterocyclic amines in the normal subject who showed the maximum increase of amine excretion. There is a considerable rise without neomycin ingestion, but no significant effect when taking the antibiotics. Chromatography showed there was, in fact, no heterocyclic amine excretion when taking neomycin (Fig. 9), the positive readings shown in Fig. 6 being due to urinary dimethylamine which is also estimated by the method. The true basal output of heterocyclic amines is given by the difference between the readings with and without neomycin. This difference is $0.63 \mathrm{mg}$./hour, a figure agreeing with von Euler's estimate (1945) of 3 to $20 \mathrm{mg}$. urinary piperidine plus pyrrolidine per day.

Fig. 7 gives the results after ornithine ingestion. Here the separation between the cystinurics and the normals is more obvious, but one of the patients received more amino-acid than the other three subjects. Ornithine hydrochloride is considerably 


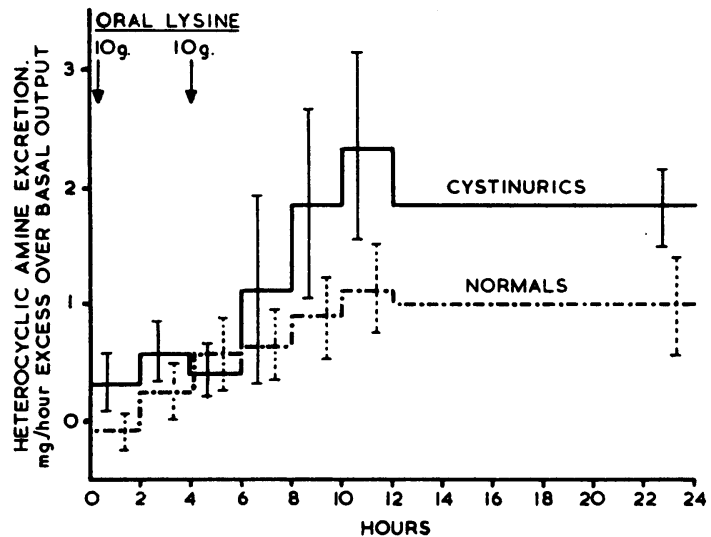

FIG. 5. Mean excretion or heterocyclic amines, expressed as mg./hour excess of basal output, in 10 normal subjects and four cystinurics after ingestion of $20 \mathrm{~g}$. lysine. The vertical lines give the standard error of the means. There is considerable scatter and, although the cystinurics excrete about twice as much piperidine + pyrrolidine as compared to normal subjects, the difference is not statistically significant. In both normal subjects and in cystinuric patients the maximum output occurs from 10 to 12 hours after ingestion of the amino-acid.

FIG. 5

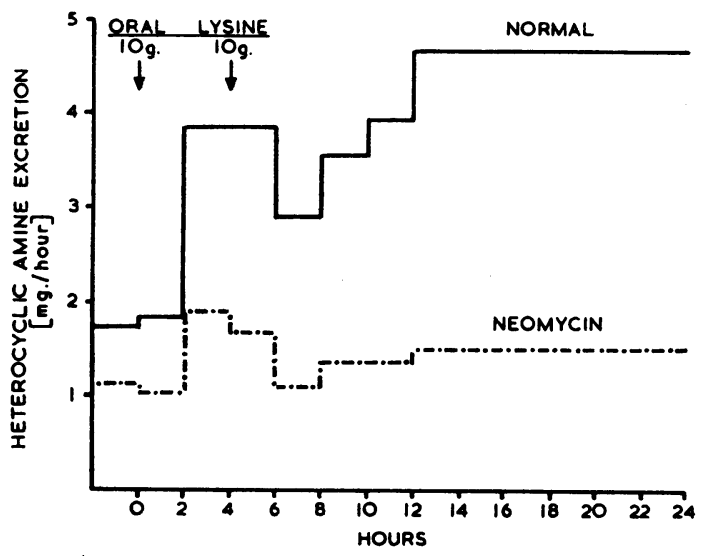

FIG. 6. Excretion of heterocyclic amines in the normal subject who showed the greatest amine output after lysine ingestion, with and without oral neomycin. There is no increase of urinary piperidine + pyrrolidine when taking neomycin, but a considerable rise when the antibiotic is not being taken. Chromatography while taking neomycin failed to show any urinary heterocyclic amine output. The values shown by the broken line represent the blank values of the method and are almost entirely accounted for by urinary dimethylamine.

FIG. 6

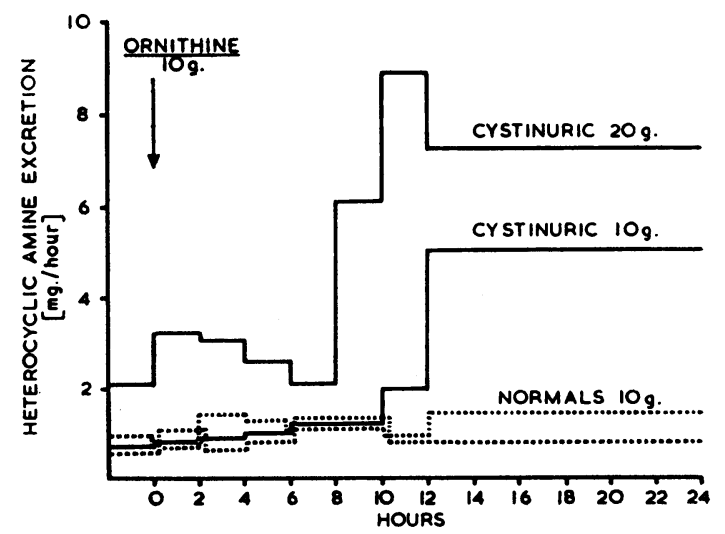

FIG. 7. Excretion of heterocyclic amines in two cystinurics and two normal subjects after ornithine ingestion. One cystinuric ingested $20 \mathrm{~g}$. ornithine whereas the other three subjects were given $10 \mathrm{~g}$. only. There is a great increase of urinary piperidine + pyrrolidine in the cystinurics but no rise in the two normal subjects. The maximal output in the cystinurics occurs 10 to 24 hours after amino-acid ingestion, and the amount of amines excreted is much greater than after lysine.

FIG. 7 
more expensive than lysine hydrochloride and was found to be more toxic, accounting for the limited number of metabolic tests using this amino-acid. The excess heterocyclic amine output in the cystinurics was $88 \mathrm{mg}$. from $20 \mathrm{~g}$. ornithine hydrochloride, and $57 \mathrm{mg}$. from $10 \mathrm{~g}$. of the amino-acid, equivalent to conversion rates of $1 \%$ and $1.35 \%$ respectively. About three times as much amino-acid is converted to heterocyclic amines after ornithine as after lysine. This might be explained by the fact that lysine is a normal constituent of dietary protein, whereas ornithine is not. The two normal subjects taking ornithine showed no significant change in output of the heterocyclic amines.

The results given by the relatively less specific extraction procedure are confirmed and extended by the chromatographic results of Figs. 8-10. The use of DNP derivatives has the great advantage of distinguishing between piperidine, pyrrolidine, and dimethylamine, but is too time-consuming to have been applied to all 160 urine specimens analysed in this investigation. In practice the basal specimens and the samples showing high heterocyclic amine output 10 to 24 hours after amino-acid ingestion were analysed by this method. Great care was taken to ensure that specimens from the same patient were collected over equal time periods, and contained amounts of creatinine not differing by more than $10 \%$. The urine of adult patients corresponding to about five minutes' excretion was a suitable quantity for analysis. By the chromatographic technique there are usually six distinct sorts of DNP derivatives of urinary amines and ammonia (Asatoor, 1960). Proceeding from the origin, the DNP derivatives are those of piperidine, pyrrolidine, ethylamine, dimethylamine, methylamine, and ammonia respectively. The fraction of DNPammonia extracted by cyclohexane is low compared to that of the DNP-amines, so that the ammonia spot is smaller than expected from the large amount of ammonia present in urine. The largest single spot in normal urine is usually that derived from dimethylamine. The procedures used in the tests did not have any effect on the output of the aliphatic amines, methylamine, ethylamine, or dimethylamine. Ammonia output was usually increased by the experimental procedure because the amino-acid hydrochlorides produce a systemic acidosis and a highly acid urine. The urinary excretion of the five amines was unaffected by alteration in acid-base

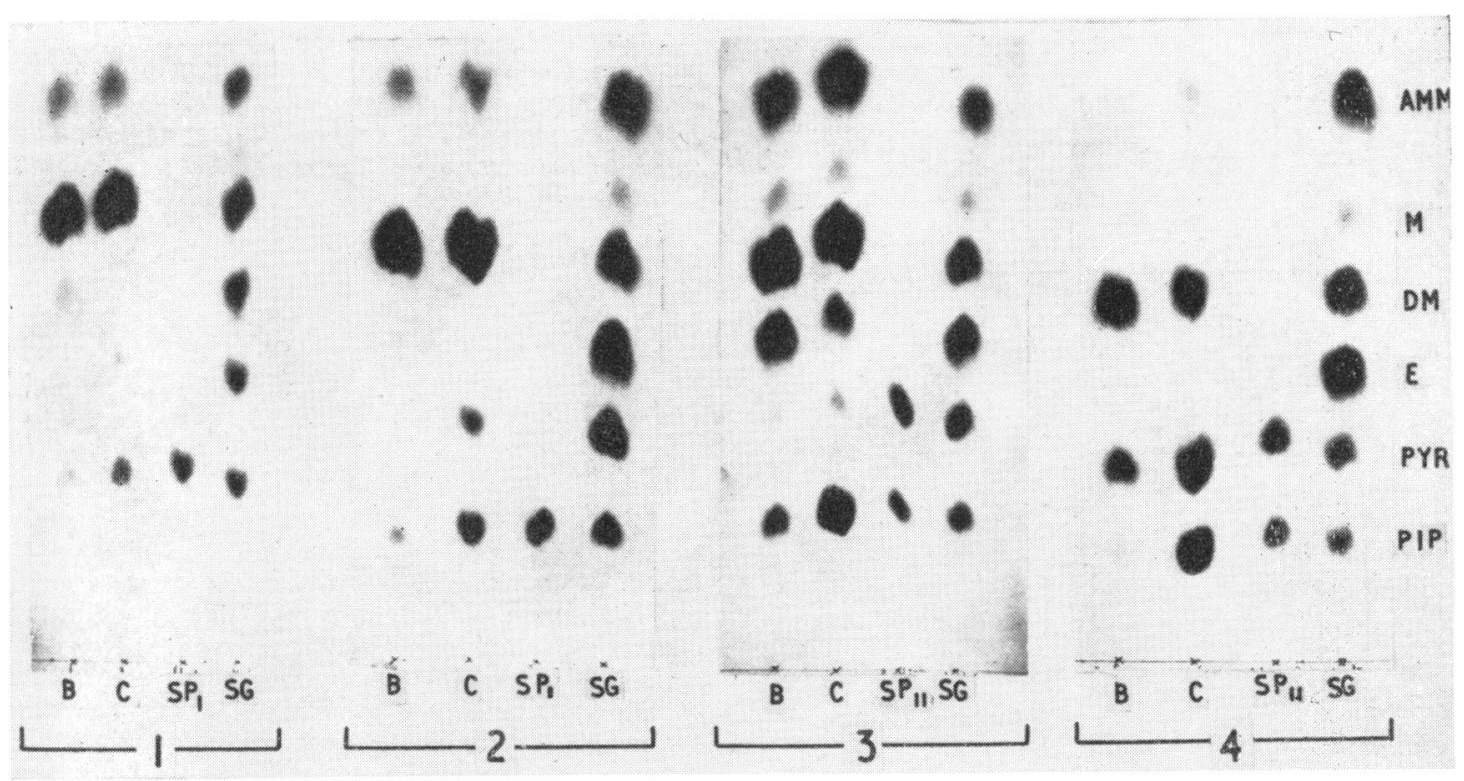

FIG. 8. Chromatograms of urine from four cystinurics before and after lysine ingestion. DNP derivatives of urinary amines and ammonia extracted by cyclohexane. Reversed phase chromatography; chloroform:methanol:water as solvent. $D N P$ derivatives photographed in ultra-violet light. $B=$ before lysine ingestion. $C=10$ to 12 hours after lysine ingestion. $S G=$ general standard of the six DNP derivatives of piperidine $(P I P)$, pyrrolidine $(P Y R)$, ethylamine $(E)$, dimethylamine $(D M)$, methylamine $(M)$, and ammonia $(A M M) . S P_{1}=$ marker of $D N P$ derivative of piperidine only; $S P_{11}=$ mixed marker of DNP derivatives of piperidine and pyrrolidine. There is a great increase of piperidine excretion after lysine, but there is also some rise of pyrrolidine output. The four chromatograms $(1,2,3$, and 4) are grouped in order of the magnitude of the response, minimum increase of amine excretion on the left and maximum increase on the right. 


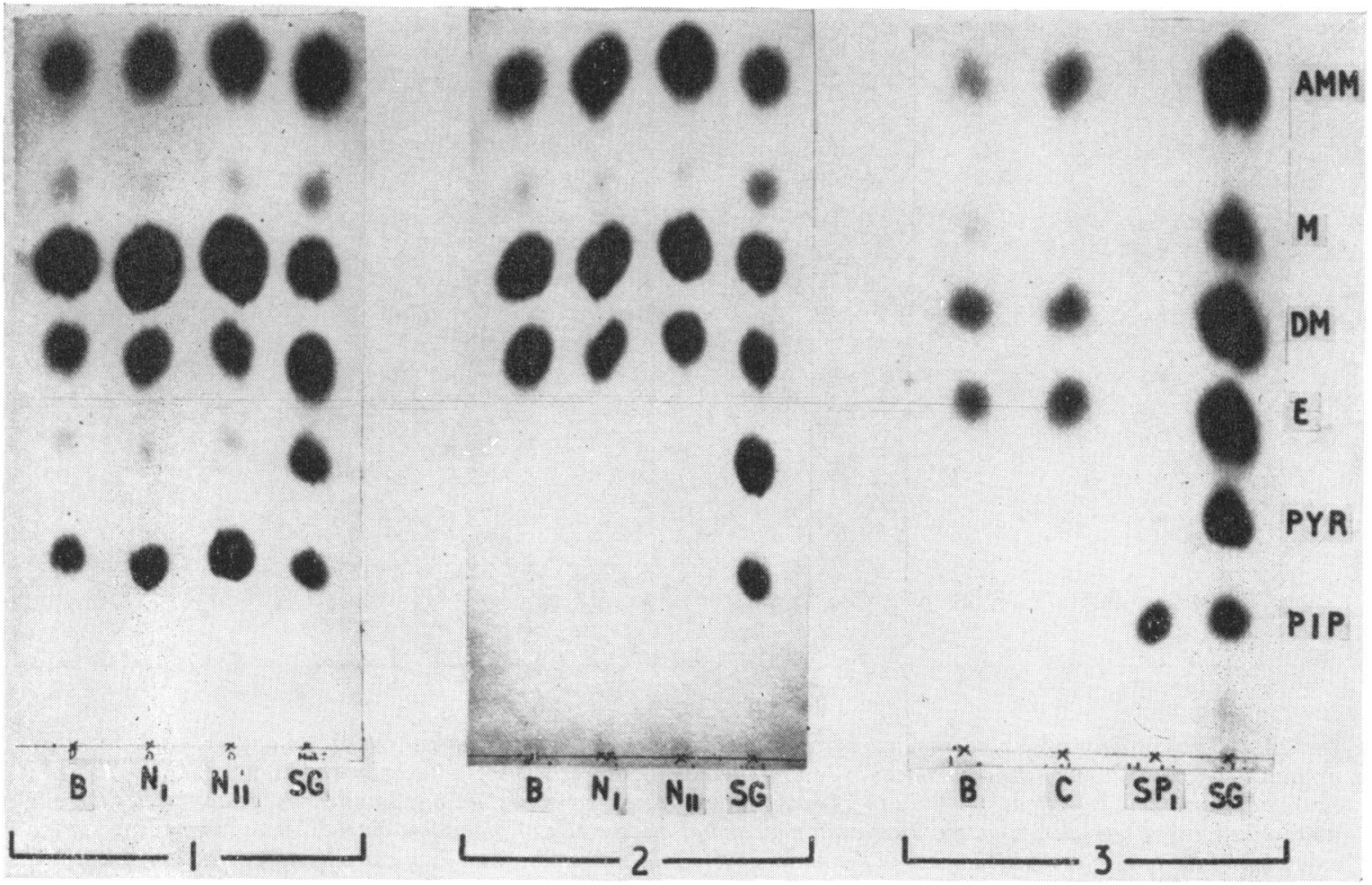

FIG. 9. Chromatograms of urine from $1=$ normal subject; $2=$ normal subject pre-treated with neomycin; and $3=a$ cystinuric patient pre-treated with neomycin, before and after lysine ingestion in all subjects. Technique as in Fig. 8. $N_{1}=10$ to 12 hours after the amino-acid; $N_{11}=12$ to 24 hours after the amino-acid. Other symbols as in Fig. 8. In chromatogram 1 there is some rise of piperidine output after lysine, but no increase of pyrrolidine. In chromatograms 2 and 3 the oral neomycin has inhibited production and excretion of both piperidine and pyrrolidine but has not influenced the output of the aliphatic amines or of ammonia.

balance. Changes in piperidine and pyrrolidine output are reported in detail.

Fig. 8 shows the chromatograms derived from the four cystinuric patients receiving lysine. They are classified in order of the magnitude of the effect produced, the one on the right labelled '4' showing the greatest rise of heterocyclic amines. In every case there was an increased output of both piperidine and pyrrolidine, although the change in the former amine was more obvious. This result was never found in a normal subject (Table I, last column). Here there was either no detectable change in amine output, or there was an increased excretion of piperidine only. The normal subject with the greatest effect is shown in Fig. 9, chromatogram 1. We interpret this difference between cystinurics and healthy controls as indicative of saturation of the intestinal transport mechanism of the cystinuric patients by a large dose of amino-acid, allowing dietary arginine to reach the colon and to be converted by bacteria to ornithine and then to putrescine (Fig. 1). Fig. 9 shows the effect of neomycin on heterocyclic amine output. Chromatograms 1 and 2 show the results obtained from the same normal subject with and without oral neomycin, and correspond to the quantitative analyses of Fig. 6. Chromatogram 3 gives the effect of neomycin in a cystinuric patient. In both cases the antibiotic causes complete disappearance of the piperidine and pyrrolidine spots, but has no effect on the other four spots. This proves that the urinary heterocyclic amines are completely dependent for their formation on bacterial action in the colon. Fig. 10 shows the results obtained from the four subjects after ornithine ingestion. In the cystinuric patients there is a great increase in the pyrrolidine spot and a smaller rise in the piperidine spot. This is again interpreted as evidence of saturation of the intestinal transport system. Excess ornithine causes both ingested ornithine and dietary lysine to reach the colon and to be converted both to cadaverine and putrescine. Ornithine ingestion by the normal 


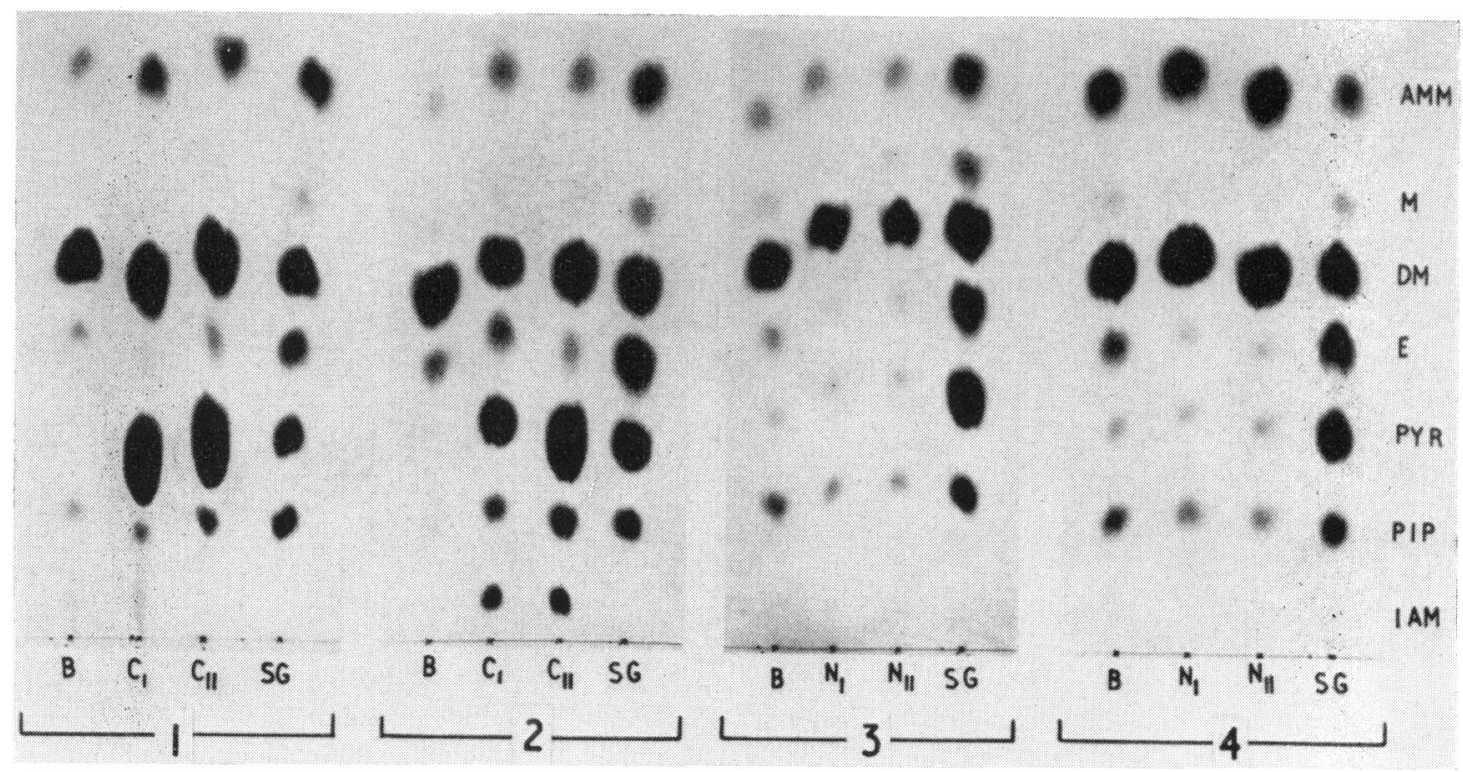

FIG. 10. Chromatograms of urine from two cystinurics ( 1 and 2$)$ and from two normal subjects (3 and 4$)$ before and after ornithine ingestion $\left(20 \mathrm{~g}\right.$. of the amino-acid in $1 ; 10 \mathrm{~g}$. in the other three subjects). Technique as in Fig. 8. $C_{1}=10$ to 12 hours after ornithine ingestion; $C_{11}=12$ to 24 hours after. Other symbols as in Figs. 8 and 9. In the cystinurics there is a great increase of pyrrolidine output after ornithine, and also some rise of piperidine output. There is no change in the excretion of the two heterocyclic amines in the normal subjects. In chromatogram 2 an extra spot, provisionally identified as the DNP derivative of iso-amylamine (IAM), has appeared below the piperidine spot after ornithine ingestion.

subjects causes no appreciable change in heterocyclic amine output. In chromatogram 2 an extra spot was found after ornithine ingestion with a lower $R_{f}$ value than DNP-piperidine. This was provisionally identified by chromatography as DNP-isoamylamine. Further work is in progress in connexion with the precise identification of this abnormal urinary amine.

\section{DISCUSSION}

The results show that the metabolic effects of ingestion of a large dose of either L-lysine or L-ornithine hydrochloride in homozygous cystinuric patients differ from those in normal subjects. In cystinurics the amino-acids are incompletely absorbed in the small intestine, and can easily be detected in the faeces. This implies defective transport of the amino-acids by the jejunal cells similar to that previously known to occur in the proximal tubule cells of the kidney. The defect is not severe enough to cause any clinical disability or signs of malnutrition. Absorption of the involved amino-acids is almost complete at ordinary rates of ingestion, and therefore the loss of amino-acids in the faeces is not excessive on a normal diet. This is of especial importance in the case of lysine which is an essential amino-acid.

Ingestion of neomycin by normal subjects produces a broad spectrum malabsorption defect (Faloon et al., 1958; Jacobson et al., 1960) involving fats, carbohydrates, iron, vitamin $B_{12}$, and nitrogenous compounds, resembling the defect of idiopathic steatorrhoea. The present results show that the increase of faecal nitrogen after neomycin ingestion is partly due to rise in faecal amino-acids. Absorption of ingested lysine was defective both in the normal subjects treated with neomycin, and in homozygous cystinuric patients without neomycin. In both instances the ingested lysine saturated the intestinal transport system for dibasic amino-acids, and excess arginine as well as lysine appeared in the faeces. By contrast, in the majority of normal control subjects the transport system could not be fully saturated with the same dose of amino-acid, and neither lysine nor arginine appeared in the faeces.

Variation in the intestinal absorption of aminoacids can be classified in three functional grades:-

1 All the amino-acid is absorbed in the upper sterile portions of the gut and therefore there is no appreciable bacterial decomposition of unabsorbed amino-acid. 
2 There is appreciable bacterial breakdown of unabsorbed amino-acid, but unchanged amino-acid is not excreted in greater amounts than the normal in the faeces.

3 There is still greater defective absorption with both increased bacterial breakdown, and loss of abnormal amounts of the amino-acid in faeces.

Obviously the boundary between 1 and 2 cannot be defined anatomically, because the level of the gut which first becomes contaminated with bacterial commensals varies from patient to patient, and at different times in the same subject. Decarboxylation of lysine, ornithine, and arginine to cadaverine, putrescine, and agmatine respectively (Fig. 1) is probably especially variable. Only certain bacteria, including $E$. coli and Lactobacilli, contain all three decarboxylases, Proteus vulgaris usually contains ornithine decarboxylase only, whilst none of the enzymes usually occur in Strep. faecalis and Clostridia (Gale, 1953). Decarboxylation is more active in an acid medium and pyridoxal phosphate is essential as a co-enzyme (Gale, 1940a). The decarboxylases are inducible enzymes, their concentration being increased by prolonged contact of the bacteria with the appropriate amino-acid substrate. Possibly the difference in diamine production by cystinurics and normals may partly be explained by induced excess of decarboxylase content of the colonic bacteria, as well as by increased concentration of amino-acid substrate in the colon. This explanation is especially likely in the ornithine experiments where one normal subject had equally severe watery diarrhoea as had the cystinuric patients, and large amounts of unabsorbed amino-acid were found in the stools. In the normal subject, however, putrescine was not detected in the faeces and there was no increase of excretion of heterocyclic amines. Further experiments involving bacterial metabolism will be necessary to solve this aspect of the problem. The present experiments would possibly have been even more conclusive if large doses of amino-acid had been administered over longer periods of time to produce maximal induction of bacterial decarboxylase. Such experiments in cystinurics might conceivably not be free from risk, as considerable amounts of potentially toxic amines were formed in the present milder experimental procedure.

After ingestion of large doses of lysine or ornithine by normal subjects there is either no increase of urinary amine output, or some increase of either piperidine or pyrrolidine alone, dependent on the amino-acid ingested. By contrast, in cystinurics there is an increase of both piperidine and of pyrrolidine, and occasionally excretion of unchanged diamine as well. Presumably if the experiments had been performed in starved cystinuric patients, there would have been increased output only of the heterocyclic amine corresponding to the particular amino-acid ingested. In fact, owing to the saturation of the jejunal transport system by a single ingested amino-acid, a mixture of lysine, arginine, and ornithine, partly derived from the diet, reached the colon, and therefore there was excess urinary output of both piperidine derived from lysine, and of pyrrolidine derived from arginine and ornithine.

The present experiments alone provide sufficient proof of a defective absorption and transport of lysine and ornithine by the jejunal cells of cystinuric patients. Strong supporting evidence is furnished by many previous observations which have been consistently misinterpreted. Von Udránszky and Baumann (1889) first reported excessive urinary and faecal output of the diamines, cadaverine and putrescine, in cystinuria. The daily urinary output of their patient ranged from 0.2 to $0.4 \mathrm{~g}$. of derived benzoyldiamine, corresponding to an excretion of 60 to $120 \mathrm{mg}$. free diamine daily. In the present experiments the maximum output recorded after a large dose of precursor amino-acid was $90 \mathrm{mg}$. of cadaverine. Shortly afterwards, Stadthagen and Brieger (1889) detected cadaverine in the urine of two other cystinuric patients. Later work was reviewed by Garrod (1908) in his classical Croonian lectures on 'Inborn errors of metabolism'. Garrod stressed the inconstancy of diamine output in both faeces and urine in cystinuric patients. He recorded that diamines were isolated by nine later investigators between 1890 and 1908, but were not found by five other workers. His own personal experience included nine cases of cystinuria, and in only four of these patients were diamines detected in the urine, including one case with faecal diamine output also. In the case recorded by Cammidge and Garrod (1900) cadaverine was found in only two of 41 separate 24-hour urine specimens. The experiments of Loewy and Neuberg (1904) are of especial interest in relation to the present observations. Whilst there was no diaminuria at ordinary times in their case of cystinuria, the corresponding diamine appeared in the urine after ingestion of $5 \mathrm{~g}$. of either lysine or arginine. Garrod and Hurtley (1906), repeating these experiments with arginine alone, failed to detect diamines in the urine of their patient. Garcia (1893) and Thiele (1907) found diaminuria in cystinurics to be increased by a high protein intake.

The former interpretation of these results is of great historical interest. Von Udránszky and Baumann (1889) considered that cystinuria was due to intestinal auto-intoxication with diamines or 'ptomaines'. Moreigne (1899) criticized this view because there was no clinical evidence of any chronic 
intestinal abnormality. While agreeing that diamines were excreted in excess by cystinuric patients, he pointed out that excretion of indican and of phenols, derived from bacterial degradation of tryptophan and of phenylalanine or tyrosine respectively, was completely normal. In retrospect, this entirely correct observation should have suggested a selective rather than a general degradation of amino-acids within the colon. It was not then known, however, that decarboxylases capable of breaking down lysine, arginine, and ornithine were not present in body cells, and in fact only occurred in man within bacterial commensals in the colon. Moreigne therefore put forward the incorrect view, later supported by the authority of Garrod (1908), that the excess diamines were produced by the same unknown metabolic defect responsible for the increased cystine excretion. The true explanation of diaminuria in cystinurics was thus postponed for 60 years. In the decade after the elucidation of the renal transport defect in cystinuria by Dent and Rose (1951), the older observations of diaminuria have been dismissed as due to bacterial decomposition of excreted amino-acids in infected urine specimens. This possibility had, however, occurred to previous workers. Cammidge and Garrod (1900) and Hele (1909) were unable to find any increase of diamines in urine specimens from cystinurics after decomposition. In the present series of experiments only one of the patients had an urinary infection, and he did not excrete diamines. The urine and faecal specimens were immediately frozen after collection to prevent any appreciable bacterial decomposition outside the body. Diaminuria was always maximal six to 10 hours after amino-acid ingestion, whereas increased amino-acid excretion chiefly occurred in earlier urine collections, within the first six hours of the experiments.

In retrospect, the difficulties of earlier investigators of diaminuria in cystinurics were due to the inconstancy of the phenomenon. In the present experiments obvious diaminuria was found only in one of five patients, and was present for a short period of time. Previous workers have relied too much on analyses of 24-hour specimens of urine rather than on selected short-term collections. In the amino-acid loading experiments the doses used 50 years ago were too low to give a clear metabolic response. The amino-acids used in these older experiments had to be prepared by the investigators themselves, in contrast to the lavish commercial supply of the present day. After ingestion of lysine or ornithine by cystinuric patients, increased output of the heterocyclic amines, piperidine and pyrrolidine, is much more constant and predictable than is diaminuria. The metabolic pathway concerned was unknown before von Euler (1945) first reported the presence of piperidine in normal human urine.

The great variability of diamine excretion in cystinurics is now easily explained. A high output of diamines is dependent on the following favourable factors:- $a, \mathrm{~A}$ high intake of lysine or arginine, whether as free amino-acids or as a high-protein $\operatorname{diet} ; b$, the presence in the colon of appropriate bacteria containing high concentrations of specific decarboxylases; $c$, a favourable acidic $p \mathrm{H}$ of colonic contents and free availability of pyridoxal phosphate as co-enzyme; $d$, a low body content of diamine oxidase which rapidly oxidizes absorbed diamines to the corresponding aldehydes.

Presumably diaminuria could be produced with more certainty by simultaneous administration of lysine or ornithine and a diamine oxidase inhibitor to a cystinuric, but such an experiment could not be guaranteed as free from risk to the patient.

In this series of experiments no observations were made of the intestinal absorption of cystine itself. Cystine and cysteic acid were not detected in chromatograms of faecal extracts after lysine or ornithine ingestion. Previous experiments (Brand, Cahill, and Harris, 1935; Brand, Cahill, and Block, 1935; Lewis, Brown, and White, 1936) have been consistently misinterpreted, but strongly support defective absorption of cystine by the gut of cystinuric patients as well as that of lysine, arginine, and ornithine. These investigators showed that ingestion of cystine, homocystine, and glutathione by cystinurics did not appreciably increase urinary cystine output, whereas methionine, cysteine, and homocysteine each caused a considerable rise. The results were incorrectly interpreted as due to an abnormality of metabolism of sulphur-containing amino-acids in cystinuria. In more recent years these important results have been attributed to the relative insolubility of cystine in the gut contents reducing the speed of cystine absorption (Dent, Heathcote, and Joron, 1954a; Dent, Senior, and Walshe, 1954b). This explanation is regarded as improbable for three reasons. It would imply a poor absorption of cystine by normal healthy subjects as well as by cystinurics, an unlikely hypothesis for an amino-acid which accounts for about $2 \%$ of the amino-nitrogen of protein foods. Homocystine is considerably more soluble than cystine (Milne, 1961) but both amino-acids are poorly absorbed by cystinurics. Neil (1959), studying absorption of sulphur-containing amino-acids in the rat's intestine, found that L-cystine was absorbed at about $70 \%$ the speed of L-cysteine, a variation which would not explain the gross difference in the effects of these two amino-acids in cystinurics. Lack of solubility would, in fact, only reduce the speed of cystine 
absorption in the gut if the amino-acid was in sufficient concentration to crystallize out within the gut lumen.

The results are more adequately explained by the present concept of a specific intestinal transport defect of dibasic amino-acids similar to the known renal tubular transport defect. Homocystine is structurally similar to cystine, both amino-acids possessing two amino-groups in each molecule. It would therefore be expected to be absorbed from the intestine less rapidly in cystinuric patients than in normal subjects. By contrast, methionine, cysteine, and homocysteine each possess a single amino-group per molecule and would be expected to be absorbed normally. Glutathione, a tripeptide containing cysteine, is a very labile compound and has a considerable lower redox potential than cysteine itself (Calvin, 1954). It is therefore possibly oxidized to the di-sulphur compound within the gut lumen, and this would form cystine after hydrolysis by gut peptidases.

Dent et al. (1954a and b) repeated Brand's work except that they analysed plasma concentration of cystine by polarographic and microbiological assays as well as measuring cystine output in the urine. At this time the view of Dent and Rose (1951) that there was a specific renal transport defect in cystinuria had not been universally accepted, and therefore the discussion in these papers is chiefly concerned with the urinary aspect of the disease. It has proved profitable to re-examine the results of Dent et al. (1954a and b) in connexion with our more general view of the transport abnormality. The results of plasma levels of cystine have been recalculated as mean increments of the basal value after ingestion of similar amounts of L- and DL-cystine, L-cysteine, and DL-methionine by cystinurics and normal subjects (Fig. 11). It is seen that after ingestion of L- and DL-cystine, plasma levels of cystine do not increase as much in cystinurics as in normal subjects. This is readily explained by an intestinal transport defect which, by analogy with the results obtained in Hartnup disease (Milne et al., 1960), would be expected to involve transport of the D-enantiomorph as well as the natural L-amino-acid. By contrast, plasma levels of cystine after ingestion of L-cysteine and DL-methionine increase more in cystinurics than in normal subjects (Fig. 11). This cannot be explained by an intestinal transport defect, but would be predicted if it is assumed that the defect is more generalized and involves transport of the amino-acids from the extracellular to the intracellular compartment, especially in the tissue of greatest quantitative importance, voluntary muscle. Our view is that cysteine and methionine are absorbed from the gut at equal rates in cystinurics

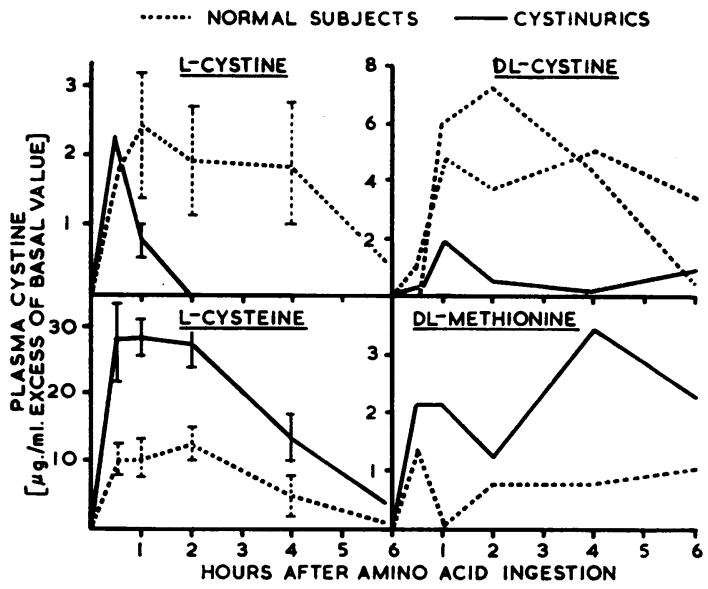

FIG. 11. Mean increments of plasma cystine after ingestion of $5.0 \mathrm{~g}$. L-cystine (upper left), $5.0 \mathrm{~g}$. DL-cystine (upper right), 6.0 g. L-cysteine HCl (lower left), and $6.2 \mathrm{~g}$. DL-methionine (lower right) respectively. The vertical lines give the standard errors of the means in the case of $L$-cystine and L-cysteine. Only three observations were made in the case of DL-cystine; the results in the case of DL-methionine are not statistically significant. After L-cystine and DL-cystine the plasma levels of cystine increase more in the normal subjects than in the cystinurics but the reverse occurs after L-cysteine and $D L$-methionine. The data are calculated from the results of Dent et al. (1954a and b).

and in normal subjects, and are rapidly metabolized to cystine, conversion being greater in the case of cysteine. The cystine formed is transferred from the blood and extracellular fluid into the intracellular space, especially of voluntary muscle, at a slower rate in the cystinurics, thus accounting for the observed higher plasma values. Obviously this hypothesis requires further investigation, and could easily be settled by following the rate of disappearance of cystine, preferably labelled with ${ }^{35} \mathrm{~S}$, from the plasma after intravenous injection in cystinurics and normal subjects. Becker and Green (1958) attempted to investigate this aspect of the disease by studies of the transfer of labelled cystine and lysine in vitro into leucocytes obtained from cystinuric patients. The entry into cells was, however, found to be identical to that into leucocytes from normal subjects.

The isolated defect of cystinuria suggests that transport of the dibasic amino-acids is completely separate from that of the monoamino-monocarboxylic amino-acids involved in the related condition, Hartnup disease. This view is supported by results in the experimental animal. Lysine and arginine cannot be observed from the gut of the rat against a transport gradient as can the 
monoamino-monocarboxylic amino-acids (Wiseman, 1955). This, however, does not necessarily prove that absorption proceeds by passive diffusion, and in fact Di Bella (1960) has recently shown that during absorption of lysine from the gut of the rat, there is concentration of the amino-acid within the wall of the gut to values above that of the contents of the gut lumen. The amino-acids involved in the transport defect of cystinuria are all concentrated within the intracellular fluid of cells from human liver and conjunctiva, and carcinoma cells in tissue culture to a much less extent that the monoaminomonocarboxylic amino-acids (Piez and Eagle, 1958). The dibasic amino-acids all show mutual competitition for the proximal renal tubular transport system (Robson and Rose, 1957), similar to their competition for intestinal transport.

There is no evidence to date that the intestinal defect of cystinuria is of more than theoretical importance. In Hartnup disease, the intestinal absorption defect is clinically of greater importance than the renal transport defect in causing the signs and symptoms of the disorder (Milne et al., 1960; Jepson and Spiro, 1960). The reverse applies in cystinuria. Repeated ingestion of large doses of lysine, arginine, or ornithine might be dangerous in cystinuric patients. Lysine hydrochloride, at a dosage of up to $40 \mathrm{~g}$. daily, has recently been advocated (Brailovsky, Silva, Del Campo, and Marusic, 1959; Rubin, Spritz, Mead, Herrmann, Braveman, and Luckey, 1960; Lasser, Schoenfeld, and Friedberg, 1960) as a source of chloride in order to potentiate the action of mercurial diuretics in the treatment of refractory oedema. The possible adverse pharmacological actions of large doses of lysine have received little attention. This paper shows that considerable quantities of lysine at high dosage may escape absorption in the small intestine, and be converted by bacteria in the colon into toxic diamines and then to heterocyclic amines. Piperidine has toxic actions resembling those of the alkaloid coniine (n-propylpiperidine), but is less poisonous than the plant alkaloid (Moore and Row, 1898). The diamines are powerful convulsants when given in high dosage to the experimental animal. Lysine toxicity would probably increase on repeated administration from induction of lysine decarboxylase within colonic bacteria. The risk of toxicity would obviously be greater in cystinuric patients. Simultaneous neomycin would, however, prevent the formation of toxic amines by sterilization of colonic contents.

\section{SUMMARY}

The effects of ingestion of large doses of lysine and ornithine hydrochlorides are compared in homo- zygous cystinuric patients and in normal control subjects. The amino-acids were less completely absorbed by the patients and a considerable fraction appeared unchanged in the faeces. By contrast, in normal subjects absorption was complete except in three individuals who had intestinal hurry with watery diarrhoea. Neomycin reduces amino-acid absorption both before and after large doses of lysine.

In cystinuric patients, but not in normal subjects, ingestion of lysine and ornithine increases the faecal output of arginine, suggesting saturation of a common intestinal transport system. The unabsorbed amino-acids are converted by colonic bacteria to the diamines, cadaverine and putrescine. These are absorbed from the colon in cystinuric patients and may occasionally occur in sufficient concentration to be easily detectable in the urine. The greater fraction of absorbed diamine is oxidized by diamine oxidase, with partial conversion to the heterocyclic amines, piperidine and pyrrolidine, which are promptly excreted in the urine. Output of the heterocyclic amines is greater in cystinuric patients after lysine or ornithine ingestion than in normal subjects. Owing to saturation of the intestinal transport system for dibasic amino-acids, lysine and ornithine ingestion in cystinurics causes increased output of both piperidine and pyrrolidine, whereas only the single heterocyclic amine corresponding to the ingested amino-acid rises in normal subjects.

The results suggest that the amino-acid transport defect known to occur in the kidney of cystinurics is also present in the gut. This view of the disease explains many apparently anomalous results obtained by previous investigators.

We should like to thank Professor E. J. King and Dr. C. E. Dalgliesh for advice, Professor C. E. Dent, Dr. I. Gilliland, and Dr. R. J. Harrison for permission to study patients under their medical care, and Dr. P. J. G. Mann for a gift of reference chemicals.

\section{REFERENCES}

Asatoor, A. M. (1960). Paper chromatography of 2, 4-dinitrophenyl derivatives of amines. J. Chromatography, 4, 144-152.

- , and Kerr, D. N. S. (1961). Amines in blood and urine in relation to liver disease. Clin. chim. Acta, 6, 149-156.

and Milne, M. D. (1961). Unpublished observations.

Baron, D. N., Dent, C. E., Harris, H., Hart, E. W., and Jepson, J. B. (1956). Hereditary pellagra-like skin rash with temporary cerebellar ataxia, constant renal amino-aciduria and other bizarre biochemical features. Lancet, 2, 421-428.

Becker, F. F., and Green, H. (1958). Incorporation of cystine and lysine by normal and 'cystinuric' leukocytes. Proc. Soc. exp. Biol. (N.Y.), 99, 694-696.

Brailovsky, D., Silva, C., Del Campo, E., and Marusic, E. (1959). The use of L-lysine monohydrochloride in the treatment of mercurial resistant edema. Amer. J. med. Sci., 238, 287-296. 
Brand, E., Cahill, G. F., and Block, R. J. (1935). Cystinuria IV. The metabolism of homocysteine and homocystine. J. biol. Chem., $110,399-410$.

,,-- and Harris, M. M. (1935). Cystinuria. II. The metabolism of cystine, cysteine, methionine, and glutathione. Ibid., 109, 69-83.

Calvin, M. (1954). Mercaptans and disulfides: some physics, chemistry and speculation. In Glutathione, a Symposium, pp. 3-30. Ed. Colowick, S., Lazarow, A., Racker, E., Schwarz, D. R., Stadtman, E., and Waelsch, H. Academic Press, New York.

Cammidge, P. J., and Garrod, A. E. (1900). On the excretion of diamines in cystinuria. J. Path. Bact., 6, 327-333.

Dent, C. E., and Harris, H. (1951). The genetics of 'cystinuria'. Ann. Eugen. (Lond.), 16, 60-87.

- - Heathcote, J. G., and Joron, G. E. (1954a). The pathogenesis of cystinuria. I. Chromatographic and microbiological studies of the metabolism of sulphur-containing amino-acids. J. clin. Invest., 33, 1210-1215.

- - and Rose G. A. (1951). Amino-acid metabolism in cystinuria. Quart. J. Med., n.s., 20, 205-219.

- Senior, B., and Walshe, J. M. (1954b). The pathogenesis of cystinuria. II. Polarographic studies of the metabolism of sulphur-containing amino-acids. J. clin. Invest., 33, 1216-1226.

Di Bella, S. (1960). Absorption of L-lysine in the small intestine of rats. Experientia (Basel), 16, 367-368.

Euler, U. S. von (1945). The occurrence and determination of piperidine in human and animal urine. Acta. pharmacol. (Kbh.), 1, 29-59.

Faloon, W. W., Fisher, C. J., and Duggan, K. C. (1958). Occurrence of a sprue-like syndrome during neomycin therapy. J. clin. Invest., 37, 893.

Gale, E. F. (1940a). The production of amines by bacteria. I. The decarboxylation of amino-acids by strains of Bacterium coli. Biochem. J., 34, 392-413.

- (1940b). The production of amines by bacteria. 3. The production of putrescine from $\mathbf{L}(+)$-arginine by Bacterium coli in symbiosis with Streptococcus faecalis. Ibid., 34, 853-857.

- (1953). Amino-acid decarboxylase. Brit. med. Bull., 9, 135-138.

Garcia, S. A. (1893). Ueber Ptomaine. Hoppe-Seylers Z. physiol. Chem., 17, 577-595.

Garrod, A. E. (1908). The Croonian lectures on inborn errors of metabolism. Lancet, 2, 142-148 and 214-220.

- , and Hurtley, W. H. (1906). Concerning cystinuria. J. Physiol. (Lond.), 34, 217-223.

Harris, H., Mittwoch, U., Robson, E. B., and Warren, F. L. (1955a). The pattern of amino-acid excretion in cystinuria. Ann. hum. Genet., 19, 196-208.

$-,-,-\longrightarrow,(1955 \mathrm{~b})$. Phenotypes and genotypes in cystinuria. Ibid., 20, 57-91.

-, and Robson, E. B. (1955). Variation in homozygous cystinuria. Acta genet. (Basel), 5, 381-390.

-_, and Warren, F. L. (1953). Quantitative studies on the urinary cystine in patients with cystine stone formation and in their relatives. Ann. Eugen. (Lond.), 18, 125-171.

Hele, T. S. (1909). Metabolism in cystinuria. J. Physiol. (Lond.), $39,52-72$.

Jacobson, E. D., Chodos, R. B., and Faloon, W. W. (1960). An experimental malabsorption syndrome induced by neomycin Amer. J. Med., 28, 524-533.

Jepson, J. B., and Spiro, M. J. (1960). Hartnup disease. In The Metabolic Basis of Inherited Disease, pp. 1338-1364. Ed. Stanbury, J. B., Wyngaarden, J. B., and Fredrickson, D. S. McGraw-Hill, New York.
Krebs, H. A., and Henseleit, K. (1932). Untersuchungen über die Harnstoff bildung im Tierkörper. Hoppe-Seylers Z. physiol. Chem., 210, 33-66.

Lasser, R. P., Schoenfeld, M. R., and Friedberg, C. K. (1960). L-lysine monohydrochloride. A clinical study of its action as a chloruretic acidifying adjuvant to mercurial diuretics. New Engl. J. Med., 263, 728-733.

Lewis, H. B., Brown, B. H., and White, F. R. (1936). The metabolism of sulfur. 23. The influence of the ingestion of cystine, cysteine, and methionine on the excretion of cystine in cystinuria. J. biol. Chem., 114, 171-184.

Loewy, A., and Neuberg, C. (1904). Uber Cystinurie. Hoppe-Seylers Z. physiol. Chem., 43, 338-354.

Mann, P. J. G., and Smithies, W. R. (1955). Plant enzyme reactions leading to the formation of heterocyclic compounds. I. The formation of unsaturated pyrrolidine and piperidine compounds. Biochem. J., 61, 89-100.

Milne, M. D. (1961). Unpublished observations.

-, Crawford, M. A., Girão, C. B., and Loughridge, L. W. (1960). The metabolic disorder in Hartnup disease. Quart. J. Med., n.s., 29, 407-421.

Moore, B., and Row, R. (1898). A comparison of the physiological actions and chemical constitution of piperidine, coniine and nicotine. J. Physiol. (Lond.), 22, 273-295.

Moreigne, H. (1899). Étude sur la cystinurie. Arch. Méd. exp., 11, 254-312.

Neil, M. W. (1959). The absorption of cystine and cysteine from rat small intestine. Biochem. J., 71, 118-124.

Piez, K. A., and Eagle, H. (1958). The free amino acid pool of cultured human cells. J. biol. Chem., 231, 533-545.

Robson, E. B., and Rose, G. A. (1957). The effect of intravenous lysine on the renal clearances of cystine, arginine and ornithine in normal subjects, in patients with cystinuria and Fanconi syndrome and in their relatives. Clin. Sci., 16, 75-93.

Rothstein, M., and Miller, L. L. (1954). The conversion of lysine to pipecolic acid in the rat. J. biol. Chem., 211, 851-858.

Rubin, A. L., Spritz, N., Mead, A. W., Herrmann, R. A., Braveman, W. S., and Luckey, E. H. (1960). The use of L-lysine monohydrochloride in combination with mercurial diuretics in the treatment of refractory fluid retention. Circulation, 21, 332-336.

Simon, C. E. (1900). Cystinuria and its relation to diaminuria. Amer. J. med. Sci., 119, 39-54.

Stadthagen, M., and Brieger, L. (1889). Ueber Cystinurie. Berl. klin. Wschr., 26, 344-347.

Strecker, H. J. (1960). The interconversion of glutamic acid and proline. III. $\Delta_{1}$-pyrroline-5-carboxylic acid dehydrogenase. J. biol. Chem., 235, 3218-3223.

Suzuki, T., and Hagihara, F. (1954). Conversion of cadaverine to piperidine by hog kidney homogenate. J. pharm. Soc. Japan, $74,546-547$.

Thiele, F. H. (1907). Concerning cystinuria and diamines. J. Physiol. (Lond.), 36, 68-80.

Udránszky, L. von, and Baumann, E. (1889). Ueber das Vorkommen von Diaminen, sogenannten Ptomainen, bei Cystinurie. Hoppe-Seylers Z. physiol. Chem., 13, 562-594.

Wiseman, G. (1955). Preferential transference of amino-acids from amino-acid mixtures by sacs of everted small intestine of the golden hamster (mesocricetus auratus). J. Physiol. (Lond.), $127,414-422$.

Wollaston, W. H. (1810). On cystic oxide, a new species of urinary calculus. Phil. Trans., 100, 223-230.

Zaimis, E. J. (1950). The synthesis of methonium compounds, their isolation from urine, and their photometric determination. Brit. J. Pharmacol., 5, 424-430. 